\title{
O PROCESSO COMO ESPAÇO DE OBJETIVAÇÃO DO DIREITO
}

\author{
Horácio Wanderlei Rodrigues*
}

\section{RESUMO}

O objeto deste artigo é analisar a possibilidade de objetivação do Direito através dos processos de interpretação jurídica, bem como através do processo jurisdicional. $O$ ponto de partida são as posições que apresentam a subjetividade como elemento central dos processos de interpretação e aplicação calcados em elementos fundamentalmente axiológicos. Como resposta a essa leitura é construída uma leitura alternativa, tendo como base o conceito de mundo 3 proposto por Karl Popper em sua obra. Dentro dessa teoria, que compõe o racionalismo crítico popperiano, o Direito deve ser localizado no mundo 3, o mundo objetivo. São também trabalhados os conceitos de verossimilhança e refutabilidade, baseados na premissa de eliminação do erro. Nessa leitura o Debate Crítico Apreciativo constitui o elemento central de objetivação do direito. É apresentada também a idéia de que o processo se constitui em locus de produção e aplicação de conhecimento e que mesmo reconhecida a subjetividade do ato jurisdicional, não é possível negar que nele também ocorre objetivação do Direito.

Palavras-chave: Aplicação do Direito. Debate Crítico Apreciativo. Interpretação do Direito. Karl Popper. Mundo 3. Objetivação do Direito. Objetividade. Processo. Racionalismo crítico. Subjetividade. Verdade. Verossimilhança.

\section{A SUBJETIVIDADE NA INTERPRETAÇÃO E APLICAÇÃO DO DIREITO}

$\mathrm{Na}$ Teoria Pura do Direito de Hans Kelsen encontramos as idéias de imprecisão significativa das palavras da lei e de pluralidade de sentidos das normas, acompanhadas de uma leitura da produção do conhecimento que separa a interpretação da Ciência do Direito da interpretação dos aplicadores do direito. A primeira seria pura ou a-valorativa ${ }^{1}$ por expressar todas as possibilidades interpretativas das normas, oriundas de imprecisão significativa, sem entretanto realizar qualquer juízo de valor ou hierarquização das mesmas. A segunda seria subjetiva. ${ }^{2}$

Luis Alberto Warat e Nilo Bairros de Brum assumem as posições kelseniadas sobre a plurissignificação das palavras e conceitos contidos nas normas jurídicas. Mas possuem uma visão crítica da separação entre produção de conhecimento científico e aplicação técnica do direito. Para ambos tanto na ciência como na prática judicial as interpretações são valorativas e o que há é apenas uma utilização retórica da ciência e dos instrumentos hermenêuticos para justificar a atuação concreta de uma determinada leitura do direito. ${ }^{3}$ 


\title{
1.10 ato interpretativo como ato redefinitório
}

Partindo da premissa que as normas jurídicas possuem imprecisão significativa, Luiz Alberto Warat afirma que todo ato interpretativo não passa de uma redefinição direta ou indireta das palavras da lei. Toda definição é uma forma de explicitar os critérios segundo os quais se pode efetuar um processo de classificação, delimitando quais os objetos que pertencem e quais os que não pertencem a uma determinada classe. Quando se estabelece que $X$, e não $Y$, é critério definitório de uma determinada classe de objetos, se está nela incluindo determinados objetos e excluindo outros. Pode-se dizer, então, que definir é estabelecer os critérios segundo os quais um signo pode ser utilizado para se referir a um determinado grupo de objetos.

Quando se utiliza a expressão redefinir, se está pensando no processo pelo qual se alteram os critérios de utilização de um signo (sua designação), possibilitando, dessa forma, uma alteração no conjunto de objetos que ele passa a incluir (sua denotação). Ou seja, há a alteração do seu significado, permitindo sua aplicação a objetos antes não considerados, ou a exclusão de objetos antes considerados. $^{4}$

Segundo Luiz Alberto Warat, os denominados métodos de interpretação da lei estudados pela hermenêutica tradicional são, na realidade, recursos tópicos para a produção de redefinições das palavras da lei, sempre determinados por fatores axiológicos:

\begin{abstract}
De forma mais ampla podemos dizer que toda vez que no uso contextual de um termo são alterados os critérios de relevância regularmente explicitados, isto é, a significação de base do aludido termo, ocorre uma redefinição. ${ }^{5}$

Para redefinir os juristas interferem diretamente sobre as significações dos termos, propondo novas regras designativas, ou realizando uma forma indireta de interferência. Na segunda hipótese, pode este modo redefinitório aparecer como um conjunto de argumentos retóricos [...] impõem-se nos contextos onde as propostas de novas significações são consideradas arbitrárias ou lingüisticamente impossíveis. ${ }^{6}$
\end{abstract}

A redefinição pode dar-se, então, de forma direta ou indireta. A vagueza e a ambigüidade, vistas como imprecisões significativas da linguagem, permitem a primeira dessas formas. Há vagueza quando um signo ou palavra não possui um sentido claro e unívoco, quando permite mais de uma leitura. Já a ambigüidade ocorre quando um termo ou texto possui mais de um significado, mas todos razoavelmente claros.

Há através da redefinição direta uma mudança expressa na definição do termo, incluindo ou excluindo critérios de sua aplicação. Essa atitude tem conseqüências diretas para o mundo do direito:

Generalizando, é possível afirmar que ao se estabelecer que $A$, e não $B$, é característica definitória de um termo contido na norma, está-se alterando as conseqüências jurídicas da mesma. ${ }^{7}$ 
Quando se decide mudar os critérios de relevância para a formação de uma classe, a definição explicativa produz um verdadeiro processo de redefinição do termo. ${ }^{8}$

Os valores jurídicos segurança e eqüidade, fundamentais para o mundo do direito, são, segundo Warat, os elementos utilizados retoricamente para demonstrar a procedência dessas (re)leituras das normas.

No que se refere à redefinição indireta, segundo Warat, ela se utiliza das variáveis axiológicas, do recurso às teorias, da adjetivação desqualificadora, da análise retórica dos fatos e das alterações sintáticas. ${ }^{9}$

As variáveis axiológicas são expressões que não possuem uma significação descritiva clara. Sua utilização, em determinadas situações concretas, associadas aos termos utilizados para descrevê-las, geram uma alteração no sentido tradicional desses termos. Quando se diz que uma sentença é injusta ou uma lei não é legítima, se está utilizando variáveis axiológicas.

As teorias jurídicas também são formas de alteração do sentido da lei. $\mathrm{Na}$ área do direito processual, a adoção na leitura e interpretação da legislação processual, de uma visão procedimentalista ou de uma visão fundada na busca do acesso à justiça, leva a atribuir-Ihe sentidos e conseqüências diferenciados.

Os adjetivos desqualificadores são aquelas expressões que anulam propriedades normalmente emprestadas a um substantivo. São adjetivos como, por exemplo, inépcia e incompetência. Uma petição inicial inepta e uma sentença proferida por juiz incompetente já não possuem os mesmos sentidos que teriam sem a sua presença. Também uma sentença nula já não é uma sentença e uma lei ilegítima pode ser considerada como não direito. Saliente-se, no entanto, que a adjetivação desqualificadora, em muitas situações, aproxima-se e até mesmo confunde-se com a utilização das variáveis axiológicas.

A análise retórica dos fatos é uma forma de redefinição dos dados e não da lei. Através dela, expõem-se os fatos valorando determinados aspectos em detrimento de outros, atribuindo-Ihes, dessa forma, determinado sentido. Ou seja, o juízo de valor utilizado na exposição, para valorar alguns aspectos e não outros, busca demonstrar como real uma determinada leitura dos fatos, mostrando-a inclusive como oriunda de uma comprovação empírica. A valorização de um exame de DNA, por ser uma prova científica, em detrimento de outras provas, é uma situação em que isso ocorre. A definição sobre qual o momento em que inicia a vida e em que momento ocorre a morte tem efeitos diretos sobre 0 enquadramento de determinados fatos no âmbito dos crimes contra a vida.

Por último, as alterações sintáticas. A redação legislativa é, em muitos momentos, falha no que se refere à correção sintática dos textos legais. Esse fato pode levar a utilização retórica dessas imperfeições, buscando com isso redefinir o seu sentido teleológico.

Segundo Warat a lei, por ser construída em linguagem natural, ${ }^{10}$ pode ser redefinida, direta ou indiretamente. Também para ele, como os métodos de 
interpretação e as teorias jurídicas são, na realidade, instrumentos redefinitórios do conteúdo das normas jurídicas, servindo para atribuir-lhes o sentido desejado pelo intérprete. Ou seja, a hermenêutica e as teorias jurídicas produzem um instrumental persuasivo que auxilia o intérprete e o aplicador do direito a convencerem os destinatários da norma de que a decisão tomada é a correta. Sua função é política e não científica, pois não levam ao descobrimento da verdade jurídica. ${ }^{11^{3}}$

Essa tese defendida por Warat é extremamente importante, pois demonstra que $o$ ato interpretativo não é um ato de descoberta, mas sim um ato de atribuição de sentido, de construção do conteúdo do ordenamento jurídico. Nessa linha de raciocínio não apenas a interpretação dos aplicadores cria direito, mas também as demais formas de produção de conhecimento que o tem por objeto o fazem, mesmo que indiretamente. A consciência desse fato é fundamental, pois permite compreender que $o$ ato de interpretação não é um ato meramente técnico, mas contém elementos axiológicos e mesmo ideológicos.

Tendo como ponto de partida as posições de Warat, é possível afirmar que:

a) o direito positivo é composto por normas que possuem um conteúdo impreciso - em outras palavras, as normas jurídicas não possuem univocidade significativa, como já afirma Kelsen em sua Teoria Pura do Direito; ${ }^{12}$

b) os métodos de interpretação não são instrumentos suficientes para eliminar as imprecisões e descobrir o real conteúdo normativo - são em realidade instrumentos retóricos para atribuir sentido às normas;

c) a atribuição de sentidos unívocos às normas jurídicas é uma ficção que busca convencer o interlocutor de que a interpretação aplicada é o próprio direito - tese já presente na Teoria Pura do Direito, onde Kelsen afirma que esse tipo de ficção é utilizada pelas teorias tradicionais na busca de consolidação do ideal de segurança jurídica $;^{13} \mathrm{e}$

d) todo ato de interpretação jurídica é um ato de atribuição de sentido, de criação jurídica, e não simples elucidação do seu conteúdo intrínseco.

É, no entanto, necessário destacar algumas observações críticas sobre essa visão do ato interpretativo defendida por Warat:

a) a redefinição dos textos legais, em especial a direta, possui limites de aceitação; esses limites estabelecem um significado de base mínimo, oriundo, de um lado, do próprio sentido textual das expressões utilizadas e, de outro, do processo de objetivação do direito;

b) o desrespeito a esses limites inviabiliza, na prática, a aceitação da nova interpretação dada à norma; $\mathrm{e}$

c) a hermenêutica jurídica clássica e a teoria do direito oferecem um farto instrumental tópico-retórico que permite que as redefinições se façam de forma indireta - o que é correto afirmar; mas de outro lado, essa forma de redefinir faz parte do próprio processo de objetivação do direito e de adequação do sentido das normas aos valores sociais, culturais e políticos, bem como de adequação às novas descobertas ocorridas nas mais diversas áreas da ciência e do conhecimento em geral. 


\subsection{Os requisitos axiológicos do ato interpretativo}

É exatamente em razão da imprecisão dos textos legais e da possibilidade de sua redefinição que $o$ ato interpretativo necessita, ao lado do cumprimento dos requisitos formais, cumprir também, no que se refere ao conhecimento produzido, determinados requisitos axiológicos. São eles que geram a legitimação da interpretação e do sentido atribuído a uma determinada norma.

Utilizar-se-á, para se referir a eles, uma classificação construída tendo como ponto partida a classificação utilizada por Nilo Bairros de Brum para referir-se ao que denomina requisitos retóricos da sentença ${ }^{14}$ sem, entretanto, com ela se identificar plenamente. Em seu conjunto esses requisitos expressam os elementos necessários no campo argumentativo para conciliar os valores segurança e equidade.

O primeiro requisito, da verossimilhança fática, exige que se demonstre a relação entre os fatos mesmos e a descrição que deles se faz. Busca dar à interpretação um efeito de verdade. ${ }^{15}$ Esse requisito tem uma vinculação muito forte com o elemento probatório. Na descrição dos fatos o intérprete utiliza o conjunto da provas existentes como um topos, ${ }^{16}$ buscando dessa forma estabelecer 0 convencimento de que os fatos ocorreram exatamente da forma que ele está descrevendo. Uma vez firmada a leitura dos fatos, a aplicação do direito torna-se bem mais simples.

O segundo requisito, da legalidade, busca dar à interpretação um efeito de segurança. Parte-se do princípio de que não é boa estratégia argumentativa colocarse contra a legalidade. A aspiração de segurança jurídica deve ser atendida, sob pena de ser a interpretação considerada ilegal ou arbitrária. Ou seja, qualquer que seja o sentido atribuído à lei, deve-se demonstrar que ele está contido, de alguma forma, na previsão genérica do legislador - ou do constituinte -; em outras palavras, deve apresentar-se como decorrente da previsão legal.

O terceiro requisito, da adequação axiológica, busca demonstrar que a interpretação atende aos valores jurídicos e sociais, cumprindo, portanto, a sua finalidade. Busca, dessa forma, dar à interpretação um efeito de justiça. $\mathrm{Na}$ dimensão axiológica está um momento extremamente importante e delicado, porque os valores contidos na significação de base da norma podem estar em conflito com os valores hegemônicos na sociedade. ${ }^{17} \mathrm{~A}$ exigência de que a interpretação, além de legal, deva ser justa, coloca o intérprete, em muitos momentos, diante do dilema de optar entre a segurança e a eqüidade, devendo, no entanto, demonstrar que não houve tal opção valorativa e que a interpretação concilia os dois valores.

O quarto e último requisito é o da imparcialidade ${ }^{18}$ do intérprete. Esse requisito visa consolidar simbolicamente a interpretação, atribuindo caráter de cientificidade aos três efeitos alcançados pelos requisitos anteriores: de verdade, de segurança e de justiça. Ele transporta para 0 ato interpretativo as idéias de objetividade e racionalidade da ciência do direito.

Esses requisitos podem, de um lado, esconder retoricamente as escolhas interpretativas, mas de outro lado cumprem uma importante função no processo de objetivação do direito, que é a de idéia reguladora, conforme será visto mais a frente. 


\section{O PROCESSO DE OBJETIVAÇÃO DO DIREITO}

$\mathrm{Na}$ primeira parte deste capítulo foram expostos posicionamentos que demonstram o reconhecimento da imprecisão dos textos legais, a impossibilidade de desvendar o seu sentido verdadeiro, bem como que os instrumentos hermenêuticos e demais estratégias utilizadas na teoria e prática do direito possuem, em grande parte, caráter argumentativo, buscando refutar interpretações ou convencer sobre o sentido correto a atribuir e a aplicar.

Entendemos, entretanto, que o sistema jurídico não funcionaria se essa forma de atribuição de sentido e aplicação fosse majoritariamente ou totalmente subjetiva. Mas a realidade é de que de fato ele - o sistema jurídico - funciona, mesmo que com falhas, como todo sistema criado pelo ser humano.

No campo do direito, como em outras áreas das Ciências Humanas e Sociais, está sempre presente uma forte presença valorativa na adoção de hipóteses, teorias e interpretações. Isso não significa, entretanto, que inexista um processo de objetivação. Valores sociais não são naturais, senão não seriam valores. Eles são construídos historicamente, como as instituições sociais. E essa construção ocorre no conflito entre hipóteses, teorias e interpretações que se apresentam como soluções no campo da existência concreta. A crítica intersubjetiva corrobora em diferentes espaços geográficos e momentos históricos aquelas que Ihe são mais aderentes, que possuem maior verossimilitude. Valores também decorrem de hipóteses e teorias explicativas, bem como de interpretações, e como tais são passíveis de crítica, de refutação e de corroboração. ${ }^{19}$

Em regimes democráticos sempre existem processos de objetivação jurídica, que podem ser mais ou menos eficientes. Sua inexistência só ocorre em situações onde não há liberdade de expressão e onde a crítica intersubjetiva não é permitida esses são os reais pressupostos do processo de objetivação: a liberdade e a crítica.

O funcionamento do sistema jurídico, tal como ocorre, pressupõe um processo de objetivação que faz com que determinados sentidos se tornem hegemônicos ou mesmo paradigmáticos; não há como construir hegemonias e paradigmas dominantes apenas pela soma de subjetividades. A objetivação ocorre pela transcendência das subjetividades.

Há mecanismos pelos quais se uniformizam interpretações e aplicações, e pelos quais gradativamente se adéquam os sentidos das normas aos valores sociais (históricos, culturais, políticos, econômicos, etc.).

$\mathrm{Na}$ busca de elucidação do que entendemos por processo de objetivação do direito, vamos utilizar alguns conceitos, classificações e idéias do racionalismo crítico de Karl Popper. Não será propriamente uma leitura popperiana do sistema jurídico, mas sim uma construção sobre a interpretação do direito que surgiu do estudo da obra desse autor. Inclui posições originais suas, interpretações, releituras e adaptações de sua obra e mesmo intuições decorrentes da sua leitura. Popper não escreveu sobre o direito. Sua preocupação central sempre foi com a produção do conhecimento científico, inclusive nas ciências sociais. ${ }^{20}$ 
Nossa preocupação neste texto não é com a Ciência do Direito - ou com a possibilidade de produção de conhecimento científico no âmbito do processo, hipótese que rejeitamos; não há no processo produção de conhecimento científico, embora nele se utilizem conhecimentos científicos produzidos em diversas ciências. O que buscamos é simplesmente mostrar como ocorre o processo de objetivação do direito via interpretação. É possível que Popper não endossasse a utilização de alguns de seus conceitos da forma aqui utilizada. Mas como ele mesmo sempre defendeu, as hipóteses e teorias possuem autonomia em relação aos seus criadores.

\subsection{0 mundo 3 e o conhecimento objetivo}

Segundo Karl Popper os objetos materiais e ideais se situam em três mundos distintos, que denomina de mundos 1, 2 e 3.

a) o mundo 1 é o dos corpos físicos e dos seus estados físicos e fisiológicos - é o mundo material;

b) o mundo 2 é dos estados mentais, das vivências subjetivas ou pessoais é o mundo psicológico; e

c) o mundo 3, em grande parte constituído de registros, é o das idéias no sentido objetivo, dos produtos da mente humana. É, em sentido amplo, o mundo da cultura humana objetivada. ${ }^{21}$

Há objetos, como as obras de arte e as construções que pertencem tanto ao mundo 1 quanto ao mundo 3; e há objetos, como os livros, cujo elemento material pertence ao mundo 1, mas cujo conteúdo pertence ao mundo 3. Popper acredita que a nossa humanidade se encontra enraizada na existência do Mundo 3 , que pode apenas ser entendida em sua relação com um Mundo 3 objetivo e com idéia da verdade objetiva. $^{22}$

O conhecimento objetivo pertence ao mundo 3, constituí a sua parte mais importante, é a que tem as repercussões mais significativas sobre o mundo 1.

\footnotetext{
O conhecimento objetivo consiste em suposições, hipóteses ou teorias, habitualmente publicadas sob a forma de livros, revistas ou palestras. Consiste também de problemas não-resolvidos e em argumentos pró ou contra diversas teorias rivais. ${ }^{23}$
}

Para Popper as teorias humanas, como conhecimento objetivo, se assemelham a uma mutação externa ao corpo, exossomática. Sendo externa, não pertence à subjetividade individual, mas à espécie como um todo, à humanidade. ${ }^{24}$

Também integra o mundo 3 a linguagem. O conhecimento objetivo é possível pela existência da função argumentativa ou crítica da linguagem, que juntamente com a sua função descritiva ou informativa ${ }^{25}$ constitui a base do mundo $3 .^{26}$ 
A função descritiva da linguagem é a que nos permite construir enunciados verdadeiros ou falsos - sobre a realidade. Seu pleno desenvolvimento pressupõe a função crítica, entendida como a argumentação crítica na busca da verdade. Enquanto a descrição pode ser ou não verdadeira, a crítica pode ser ou não válida. ${ }^{27}$

O mundo 3 ao mesmo tempo que é criação humana, é também autônomo. Isso significa que ele contém elementos que não produzimos de forma direta, que são consequências não intencionais do que fizemos. Ele nos dá mais do que aquilo que damos a ele; é a obra oferecendo sugestões ao criador. Mas ele não é apenas autônomo, é também real; as teorias em si, as coisas abstratas, são reais porque podemos interagir com elas. ${ }^{28}$

\begin{abstract}
Não obstante os vários domínios ou áreas do mundo 3 surgirem como invenções humanas, aparecem também, na qualidade de conseqüências involuntárias destas, os problemas autônomos e suas possíveis soluções. Tais problemas existem independentemente da consciência que temos deles mas podemos descobri-los no mesmo sentido em que descobrimos outras coisas, novas partículas elementares ou montanhas e rios desconhecidos, por exemplo.

Quer dizer que temos possibilidades de extrair mais do mundo 3 do que aquilo que introduzimos nele. Ocorre uma acção de dádiva e recebimento entre nós próprios o mundo 3 , recebendo-se muito mais do que aquilo que se dá. 29
\end{abstract}

O mundo 3 tem uma influência muito forte sobre o mundo 1; é um grande amplificador dos efeitos do mundo 2 sobre o mundo 1 - todos os atos realizados no mundo 1 sofrem a influência de como o mundo 2, o mundo da subjetividade, compreende o mundo 3. Ou seja, é através do mundo 2 que o mundo 3 atua sobre o mundo 1. Segundo Popper o eu está ancorado no mundo 3. Há um circuito permanente de transferência de energia entre nós e o mundo 3, e a relação que mantemos com o mundo 3 não pode ser compreendida sem considerarmos o fato de que possuímos liberdade. Não há interação direta entre o mundo 1 e o mundo 3; as relações entre eles sempre ocorrem tendo a mediação do mundo $2 .^{30}$

\footnotetext{
Não é possível compreender o mundo 2, isto é, o mundo povoado pelos nossos próprios estados mentais, sem que se entenda que a sua principal função é produzir os objectos do mundo 3 e ser influenciado pelos objectos deste último. Com efeito, o mundo 2 interage não só com o mundo 1, como Descartes pensava, mas também com o mundo 3; e os objectos deste exercem influência sobre o mundo 1 apenas através do mundo 2, que actua como intermediário. ${ }^{31}$
}

Considerando a relativa autonomia do mundo 3 , a teoria popperiana dos três mundos abre um campo bastante amplo para o estudo e busca de compreensão dos processos de interpretação e mesmo de atuação e aplicação do direito, e de todos os problemas atinentes à argumentação e à hermenêutica jurídicas. Situando o direito na teoria dos três mundos de Popper, podemos dizer:

a) mundo 1 - nele ficam situados os códigos, diários oficiais e outros meios de divulgação nos quais estão impressos os textos normativas, bem como 
aqueles nos quais estão publicados os atos de aplicação do direito, como os autos dos processos judiciais;

b) mundo 2 - nele ficam os valores e decisões individuais sobre relações, comportamentos e outras atividades regradas pelo direito; é onde são valoradas as normas e decididas as conseqüências do direito a serem realizadas no mundo 1 ;

c) mundo 3 - nele está situado o conteúdo do direito - as hipóteses, conjecturas e teorias que serão aplicadas no mundo 1 através da mediação do mundo 2; nele também estão os problemas jurídicos e os problemas de todas as ordens que necessitam de uma solução através do direito; é possível inclusive dizer que nele estão as normas jurídicas, que são a positivação de hipóteses e teorias da área do direito; é nele que se encontra o direito mesmo, enquanto conhecimento objetivo.

Para Popper conhecimento objetivo é aquele que está exposto à crítica intersubjetiva - como integrante do mundo 3 autônomo - e que é passível de refutação e corroboração; não é mais mera proposição subjetiva do seu autor, já adquiriu autonomia em relação a ele. E subjetivo é o conhecimento que não pode ser objeto de crítica intersubjetiva, não pode ser testado e refutado ou corroborado.

Estando as teorias jurídicas no mundo 3 e não nos mundos 1 e 2, nos mundos físico e da subjetividade, são elas conhecimento objetivo. São criações da subjetividade do mundo 2 , mas uma vez publicizadas passam a integrar o mundo 3 . Ao aplicar o direito no mundo 1, interpretado no mundo 2 pelas lentes dessas teorias, a subjetividade recebe do mundo 3 conhecimentos que the são externos. Essa aplicação, embora subjetiva, não é mais puramente subjetiva. Faz parte de um processo de objetivação do direito. Nesse processo não chegamos à verdade, mas gradativamente nos aproximamos dela.

\subsection{Verdade e verossimilhança}

Segundo Popper "denominamos uma proposição 'verdadeira' quando ela concorda com os fatos ou corresponde aos fatos, ou quando as coisas são tais como a proposição descreve". ${ }^{32}$ Esse conceito é denominado de conceito objetivo ou absoluto de verdade e pressupõe uma visão realista de mundo.

Para ele a verdade é e deve ser a meta da pesquisa científica, mas com a consciência de que nunca saberemos se a atingimos ou não - todo conhecimento é hipotético, conjectural. A verdade é algo que se buscamos, não algo que possuímos. Não há critérios de verdade, não há uma operação que permita descobrir se uma coisa é verdade ou não. ${ }^{33}$

Mas há critérios de falsidade e podemos saber onde ela não está. É possível, portanto, um critério racional de progresso na busca da verdade, pela eliminação de lugares onde ela não está. Nesse contexto, a verdade ocupa na teoria popperiana o lugar de idéia reguladora da produção do conhecimento através da crítica intersubjetiva. A idéia de verdade diz respeito à descrição e à informação, mas surge apenas na presença de argumentos e da crítica. ${ }^{34}$

Surge então o que Popper denomina de idéia de conteúdo de verdade de uma teoria e sua aproximação à verdade. Essa aproximação da verdade ele denomina de 
verossimilhança ou verossimilitude. ${ }^{35}$ A medida que aprendemos sobre o mundo pela refutação das teorias falsas e eliminação dos erros, através do processo de tentativa e erro, aumentamos o conteúdo de verdade das novas teorias, elas se aproximam mais da verdade do que as anteriores porque delas foi expurgado um maior número de erros. ${ }^{36}$

\begin{abstract}
Que a idéia de verdade rege a discussão crítica pode ver-se no facto de se discutir criticamente uma teoria na esperança de eliminar teorias falsas. Isto prova que somos guiados pela idéia de procurar teorias verdadeiras. ${ }^{37}$

A idéia de aproximação à verdade - tal como a idéia de verdade enquanto princípio regulador - pressupõe uma visão realista de mundo. Não pressupõe que a realidade seja como as nossas teorias científicas a descrevem, mas pressupõe que existe uma realidade e que nós e as nossas teorias - que são idéias que nós próprios criamos e por isso são sempre idealizações - nos podemos aproximar cada vez mais de uma descrição adequada da realidade, se empregarmos o modelo de quatro fases de tentativa e erro. ${ }^{38}$
\end{abstract}

O processo de objetivação pelo qual nos aproximamos da verdade só pode compreendido dentro do contexto de aceitação da existência do mundo 3 autônomo e objetivo. É na relação de trocas entre os mundos 2 e 3 e de mediação entre o mundo 3 e o mundo 1 pelo mundo 2 que refutamos hipóteses e teorias - e também interpretações - que não possuem aderência com a realidade e corroboramos determinadas hipóteses, teorias e interpretações que possuem mais verossimilitude do que outras.

$E$ isso não é diferente no âmbito da interpretação e da aplicação do direito. Também no mundo jurídico há processo de aproximação da verdade pela refutação de hipóteses, teorias e interpretações.

\title{
2.3 Refutabilidade e eliminação do erro
}

Segundo Popper todos os seres vivos, das plantas ao ser humano aprendem por tentativa e erro - essa é a base de sua epistemologia evolutiva. ${ }^{39}$ Nesse contexto geral de aprendizado e evolução ele apresenta um modelo de três fases: ${ }^{40}$ a) o problema; b) as tentativas de solução; e c) a solução. ${ }^{41}$

Segundo Popper, esse modelo também é aplicável à ciência. O que distingue a ciência humana do conhecimento biológico é a aplicação consciente do método crítico, possível pelo desenvolvimento da linguagem humana - a ciência nasce com a invenção da discussão crítica. É essa linguagem que permite a exteriorização do pensamento do indivíduo, propiciando a sua objetivação. Com isso, o erro, que na evolução biológica eliminava o indivíduo ou a espécie, na evolução do conhecimento humano elimina as teorias, mas preserva o seu autor. ${ }^{42}$

Do modelo de três fases, característico do aprendizado biológico, Popper avança para o modelo de quatro fases, característico da ciência, e que apresenta da seguinte forma: $\mathbf{P}_{\mathbf{1}} \rightarrow \mathrm{TE} \rightarrow \mathrm{EE} \rightarrow \mathbf{P}_{\mathbf{2}}{ }^{43}$ 
Nele $\mathbf{P}_{\mathbf{1}}$ é o problema inicial, TE é a teoria explicativa, hipótese ou conjectura, EE é a fase de testes, na busca de refutação da teoria (é onde buscamos testar a hipótese através da crítica), ${ }^{44}$ e $\mathbf{P}_{2}$ é novo problema oriundo dos resultados da experiência (na realidade podem ser vários novos problemas, $P_{2}, P_{3}, P_{4}$, e assim sucessivamente). ${ }^{45}$ Traduzido em quatro palavras: problemas, teorias, críticas, novos problemas. Dessas quatro categorias, a mais importante é eliminação de erros pela crítica. ${ }^{46}$

Com esse modelo Popper substitui a tradicional busca pelas fontes do conhecimento, pelo processo de solução de problemas por tentativa e eliminação de erros. Esse método é regra geral referido pelos autores de metodologia científica como hipotético-dedutivo. ${ }^{47}$

Quando se parte de um problema, que pode ser teórico ou prático, e se constroem hipóteses explicativas (teorias, conjecturas), se estabelecem possibilidades das quais são deduzidas as conseqüências práticas - esse processo permite refutar as hipóteses que se aceitas levariam a resultados inadequados ou indesejáveis, ou rever aquelas que já foram adotadas. Através desses testes tentativa e erro, nova tentativa, e assim sucessivamente - é possível uma aproximação da verdade - que Popper chama de verossimilitude -, permitindo a refutação das hipóteses inadequadas e a corroboração ${ }^{48}$ da melhor hipótese dentre as testadas.

Para Popper o método de tentativa e erro permite enfrentar todos os denominados problemas epistemológicos - sua utilização não afirma a verdade de teorias com base em enunciados singulares, ou seja, não são generalizados os resultados de conclusões verificadas em experiências; mas sua utilização permite a refutação de teorias falsas. Além disso, segundo ele, a utilização do método materializado no esquema quadripartido apresentado permite nos elevarmos por nossas próprias forças. É ele um instrumento de autotranscendência por meio da seleção e da crítica racional. ${ }^{49}$

O método de tentativa e erro é o mecanismo pelo qual as teorias construídas subjetivamente no mundo 2, uma vez publicizadas e incorporadas ao mundo 3 , retornam através do mundo 2 para serem testadas no mundo 1 . Através desse método de refutação e corroboração de teorias integrantes do mundo 3 ocorre o processo de objetivação do conhecimento através da crítica intersubjetiva, o que não é exclusivo das ciências da natureza, pois ocorre também nas ciências sociais e mesmo nas áreas do conhecimento de questionável cientificidade.

A possibilidade de utilizar-se ou não testes empíricos para refutar ou corroborar uma hipótese ou teoria não retira do processo de crítica ao qual ela é submetida o resultado de objetivação do conhecimento que é inerente à crítica intersubjetiva. ${ }^{50} \mathrm{E}$ é por essa razão que o seu método é aplicável às interpretações jurídicas, mesmo que elas não sejam científicas, adotado como critério de cientificidade a possibilidade de teste empírico. 


\subsection{Debate crítico apreciativo e objetivação do direito}

Embora possa existir a tentativa de justificar ou provar a verdade de determinadas interpretações com base em experiências pessoais, a sua publicidade permite a crítica intersubjetiva, e a conseqüente refutação. Experiências subjetivas, convicções, crenças, sentimentos, não podem em nenhuma circunstância justificar um enunciado, as relações lógicas existentes dentro de cada sistema de enunciados, ou aquelas existentes entre vários sistemas de enunciados.

Para Popper, existindo objetividade dos enunciados básicos, poderá ocorrer uma crítica racional. Em toda discussão racional, segundo Popper, o método que deve ser utilizado "é o de enunciar claramente o problema e examinar, criticamente, as várias soluções propostas." 51

No âmbito dos processos de produção do conhecimento é nossa tarefa buscar sempre hipóteses que melhor expliquem os problemas, indicando assim novas alternativas de solução. Para isso é necessário reconhecer e eliminar os erros. 0 instrumento do progresso é a crítica. O impacto das teorias sobre nossas vidas pode ser devastador - por isso é necessário testá-las através da crítica. A atitude crítica exigida no processo de produção do conhecimento é caracterizada pela disposição de modificar a hipótese, testá-la e mesmo refutá-la. ${ }^{52}$

$\mathrm{Na}$ área do direito, como em qualquer outra, a objetividade e a racionalidade não decorrem da objetividade e da racionalidade das pessoas dos juristas, que são seres humanos, e como tais subjetivos, irracionais e algumas vezes passionais; mas sim da racionalidade, identificada na atitude crítica face aos problemas - a busca da eliminação de erros através da crítica intersubjetiva é que permite a gradativa construção do conhecimento objetivo.

\footnotetext{
Mas, tal como todos os racionalistas pensantes, não afirmo que o homem seja racional. É óbvio, pelo contrário, que mesmo o homem mais racional é altamente irracional em muitos aspectos. A racionalidade não é patrimônio do homem nem um facto acerca dele. Trata-se de uma tarefa que o homem tem de realizar, uma tarefa dificultosa e cheia de restrições; mesmo que parcial, será difícil conseguir a racionalidade. ${ }^{53}$
}

Para Popper, como visto anteriormente, a discussão crítica é regida por idéias reguladoras. ${ }^{54}$ Isso não é diferente na área do direito. São idéias reguladoras fundamentais para o a produção do conhecimento na área do direito: verdade, segurança (presente especialmente na idéia de legalidade) e justiça, dentre outras; a essas, no campo do direito Processual, pode-se acrescentar a idéia de acesso à justiça.

Toda interpretação jurídica é realizada na busca de justiça e de segurança. No discurso individual, subjetivo, isso até pode ser retórico. Mas no conjunto dos debates acadêmicos e mesmo na prática profissional há a transcendência do puramente subjetivo, através da crítica intersubjetiva. Os problemas, as hipóteses, teorias e interpretações jurídicas passam a habitar o mundo 3 autônomo, deslocados da pura subjetividade. 
Exemplo que pode ser dado na área do direito de como o conhecimento produzido subjetivamente, uma vez publicizado passa a habitar o mundo 3 , adquirindo autonomia e podendo voltar para atuar no mundo 1, relido pelo mundo 2, em situações não previstas pelo seu autor, é a caracterização da coisa julgada como qualidade da sentença, teoria desenvolvida por Liebman. O autor que construiu essa hipótese provavelmente nunca pensou na sua aplicação, décadas depois, para justificar a possibilidade da adoção da denominada flexibilização ou relativização da coisa julgada - mas isso ocorreu exatamente porque as teorias jurídicas, presentes no mundo 3, transcendem seus criadores, podendo inclusive oferecer ao mundo 2 mais do que dele receberam. Esse processo, realizado através da crítica intersubjetiva, é o processo pelo qual o direito se objetiva.

O instrumento de progresso e expansão do conhecimento é a crítica - a atitude crítica como processo de escolha, de decisão. Se não podemos justificar racionalmente uma teoria, podemos justificar racionalmente uma escolha. Através da crítica - autocrítica e crítica intersubjetiva - analisamos a validade ou não dos argumentos. O Debate Crítico Apreciativo (DCA) - denominação utilizada por Popper - permite decidir quais explicações e soluções devem ser inteiramente eliminadas, quais devem ser parcialmente eliminadas e quais sobrevivem, mesmo que provisoriamente..$^{55}$

Em oposição à atitude crítica, há a atitude dogmática, que se caracteriza por buscar confirmar sempre uma hipótese, teoria ou interpretação e afastar todas as tentativas de refutá-la. Popper, referindo-se especificamente ao conhecimento científico, destaca que é necessário não descartar integralmente a atitude dogmática; sem a defesa da velha teoria não haveria como testar adequadamente a força explicativa da teoria apresentada em sua substituição. ${ }^{56}$

\begin{abstract}
A atitude dogmática de aderir a uma teoria enquanto é possível é muito significativa. Sem ela nunca poderíamos descobrir o que existe numa teoria - precisaríamos abandoná-la antes de ter tido uma oportunidade real de verificar sua força; em consequência, nenhuma teoria poderia jamais funcionar no sentida da ordenação do mundo, preparando-nos para eventos futuros, chamando nossa atenção para acontecimentos que de outro modo nunca observaríamos. ${ }^{57}$

[...] um montante limitado de dogmatismo é necessário ao progresso; sem um esforço sério pela sobrevivência no qual as velhas teorias são defendidas tenazmente, nenhuma das teorias concorrentes podem mostrar seu vigor, isto é, seu poder explanatório e seu conteúdo de verdade. O dogmatismo intolerante, porém, é um dos principais obstáculos à ciência. ${ }^{58}$
\end{abstract}

Nesse sentido, uma dose moderada de atitude dogmática é fundamental, pois permite o aprofundamento do Debate Crítico Apreciativo e uma maior aproximação da verdade - uma maior objetivação do conhecimento.

O processo de objetivação pelo qual passa o direito, por meio do Debate Crítico Apreciativo, faz parte - juntamente com os processos de objetivação presentes em todas as áreas -, do projeto humano, alicerçado na capacidade de se transcender que caracteriza a humanidade e cada um dos indivíduos que a integram - mesmo que esses sejam naturalmente irracionais e subjetivos. 
A cultura humana, em sentido lato, incluindo o direito, é uma mutação exossomática que possibilita ao ser humano realizar escolhas. Em regimes democráticos não deriva de mera violência simbólica ou física, mas da objetivação do conhecimento.

\section{CONSTITUIÇÃO E PROCESSO DE OBJETIVAÇÃO}

Para que se possa ampliar o processo de objetivação na área do direito é necessário a inexistência de uma leitura dogmática dos institutos e normas jurídicas. É necessário que se aceite a crítica e a possibilidade de refutação dos denominados marcos teóricos.

De outro lado, a inexistência de base empírica (pelo menos direta) não impede o processo de crítica, refutação e corroboração, mas exige a adoção de elementos que permitam uma referência de teste das hipóteses, teorias e interpretações propostas para a solução de problemas. Entendemos que esse elemento que permite a refutação e a corroboração está presente nos valores positivados na Constituição e, portanto, na ilegitimidade ou legitimidade das normas infraconstitucionais e dos atos de aplicação do direito - mas conscientes de que o processo de objetivação do direito pode levar à redefinição de normas contidas na própria Constituição para adequá-las às mutações ocorridas na sociedade à qual serve.

Também é necessário destacar que valores constitucionais como a liberdade e a igualdade foram historicamente corroborados pela refutação empírica ocorrida no processo histórico da humanidade. A gradativa refutação dos determinismos, de um lado, e a refutação de idéias como a de superioridade racial e a de diferença de qualidade pela origem de classe ou casta, de outro, afirmaram historicamente os valores liberdade e igualdade. Da mesma forma a corroboração da democracia como melhor regime de governo ${ }^{59}$ decorre das conseqüências empíricas das diversas formas de centralismo, autoritarismo e totalitarismo presentes na história da humanidade.

Esses exemplos permitem perceber que mesmo valores podem refutados e corroborados por experiência empírica. É 0 que também ocorre contemporaneamente com a crescente legitimação da idéia de preservação do meio ambiente e a refutação da idéia de utilização desregrada dos recursos naturais.

A Constituição não é um mero texto em branco ao qual pode ser atribuído qualquer sentido. Ela expressa valores claros dentro de um estado democrático de direito. Mas é também um texto que possui imprecisão significativa, sendo seus sentidos emprestados pelo momento histórico em que foi escrita e pelo contexto na qual possui vigência. Também ela se objetiva no processo geral de objetivação do direito.

Os valores e princípios constitucionais são referenciais suficientes - em cada momento histórico - para o processo de objetivação, permitindo a refutação e corroboração de hipóteses e teorias, bem como das interpretações realizadas pelos 
órgãos aplicadores do direito. Eles funcionam como diretrizes das idéias reguladoras de verdade, segurança e justiça.

Esses valores exigem adequada regulamentação infraconstitucional, adequada interpretação teórica das normas que integram o sistema jurídico e adequada utilização pelos órgãos aplicadores.

Nesse sentido, a Constituição coloca limites reais, quer à interpretação teórica do direito (Doutrina, Ciência Jurídica, Teoria do Direito), quer na sua aplicação pelo Poder Judiciário. Ela contém as diretrizes dos principais elementos regulares do processo de objetivação do direito.

\section{O PROCESSO COMO LOCUS DE PRODUÇÃO DE CONHECIMENTO}

Há a imprecisão dos textos legais e a impossibilidade de lhes atribuir sentidos unívocos ou verdadeiros; mas isso não implica a aceitação de que a interpretação e a aplicação do direito sejam atividades meramente subjetivas; há através dessas atividades um processo de objetivação do direito, como já visto.

Embora o processo de objetivação do direito e do direito processual se dê em grande parte através do Debate Crítico Apreciativo existente no mundo acadêmico, através da doutrina e da construção de hipóteses explicativas e modelos teóricos, não há como negar que o processo jurisdicional empírico, onde também há crítica intersubjetiva, mesmo que restrita às partes, também é espaço de objetivação.

O direito ao ser aplicado no mundo 1, mediado pela subjetividade do mundo 2 , não é mais a mera subjetividade desse mundo, mas a objetivação oriunda do embate das subjetividades, que retorna através de um ato de aplicação, ato esse que já estará limitado na sua subjetividade pelas possibilidades constituídas no mundo 3 , o mundo objetivo.

\subsection{Processo e verdade}

Questão de grande interesse quando se trata da interpretação da lei e da sua aplicação, refere-se ao problema da verdade. No campo processual torna-se ela ainda mais atraente, tendo em vista ser o processo um lugar privilegiado de produção de conhecimento, ${ }^{60}$ em especial o jurídico, mas também um espaço com maiores possibilidades de presença de elementos subjetivos.

Se o objetivo do processo fosse atingir a verdade, então ter-se-ia um problema, tendo em vista a impossibilidade de alcançá-la, mesmo através do Debate Crítico Apreciativo. Mas esse, com certeza, não o é. A busca da verdade é idéia reguladora, mas o objetivo do processo é resolver conflitos de interesses, com justiça, mantendo dessa forma a ordem social através da afirmação do direito, mas não de qualquer direito.

Quanto mais efetivo for o Debate Crítico Apreciativo, mais próxima da realidade poderá ser a aplicação do direito por parte do juiz. No entanto, a subjetividade do ato 
de interpretação da lei e dos fatos, vinculada à inexistência, na prática, da neutralidade judicial, demonstram a impossibilidade de se garantir, de forma peremptória, que essa aplicação se dará exatamente de acordo com a realidade. Ao lado disso, é necessário reconhecer que a crítica intersubjetiva em muitos momentos inexiste, como nas situações de revelia.

Para minimizar a presença da subjetividade e ampliar a aproximação da verdade, através da crítica intersubjetiva, é necessário quando da elaboração e da interpretação da legislação processual sempre privilegiar a construção que garanta um sistema capaz de garantir um contraditório eficaz e de produzir um conhecimento que seja o mais adequado para que o processo atinja seus objetivos.

Um processo com as mais amplas garantias de manifestação das partes e de produção de provas - portanto com Debate Crítico Apreciativo - certamente pode produzir um conhecimento de melhor qualidade e mais próximo da realidade, trazendo maior segurança.

A constatação de que não é possível o conhecimento da verdade no âmbito do processo - como de resto em qualquer espaço de produção do conhecimento humano - mas apenas a verossimilhança, aliada à consciência de que a verdade não é em si o objetivo do processo, não impede que nele ocorra processo de objetivação. É certo que há processos nos quais há decisões preponderantemente subjetivas; isso faz parte da realidade. Mas o mesmo ocorre inclusive na Ciência, mesmo nas ciências mais objetivas como a Física.

\subsection{Objetivação do direito via processo}

Em toda relação cognoscente individual, como nas situações de aplicação do direito via processo, o produto final - o conhecimento produzido - sempre será fruto da subjetividade do mundo 2 , mas também da objetividade do mundo 3.

O processo jurisdicional, embora normalmente não seja analisado e nem visto sob esse prisma pelos processualistas, é um método (instrumento) de produção de conhecimento. Tanto é assim, que o processo jurisdicional, em sua espécie mais característica, denomina-se processo de conhecimento. Há, portanto, uma relação cognoscente.

A legislação e os fatos trazidos ao processo podem ser lidos e interpretados de diversas formas. Autor e réu têm, com certeza, análises diferenciadas de um mesmo fato e propostas de soluções jurídicas não coincidentes para o problema a ser solucionado. Nesse sentido, o processo funciona como um espaço no qual há Debate Crítico Apreciativo - mesmo que circunscrito às partes -, presente na efetivação do contraditório e da ampla defesa. Isso permite chegar ao conhecimento mais próximo possível da realidade.

No processo jurisdicional a objetivação ocorre duplamente. Em primeiro lugar é a objetivação do próprio direito processual, que passa pelo processo de crítica intersubjetiva, no campo teórico, na discussão acadêmica e, de forma concreta, na sua aplicação, quando muitas vezes diferentes posições acadêmicas novamente se contrapõem. Em segundo lugar é espaço de objetivação, no caso concreto, do 
próprio direito material, visto que nesse momento as diferentes posições acadêmicas serão contrapostas novamente, para a refutação de uma ou mais e a escolha, pelos órgãos aplicadores, de outra, que naquele momento histórico, espaço geográfico e contexto cultural, social, político e econômico seja vista como a mais adequada para a solução do conflito.

E há o sistema recursal, através do qual o Debate Crítico Apreciativo é aprofundado. Através da apreciação de argumentos apresentados nos recursos se refutam e corroboram teses. A construção da jurisprudência é resultado do processo de objetivação. Mas não é a verdade sobre o direito. Uma vez publicizadas as decisões, passam elas a integrar o mundo 3 e se tornam objeto da crítica intersubjetiva, podendo ter seu conteúdo refutado, não mais no campo do caso específico, mas no campo geral do conhecimento e na aplicação do direito em novos processos semelhantes ou idênticos.

Há diversas situações em que a interpretação dos órgãos aplicadores do direito se torna objeto de intenso Debate Crítico Apreciativo, gerando em grande parte avanços no processo de objetivação do direito. São exemplos contemporâneos as decisões que aplicam a tese da flexibilização ou relativização e às relativas às uniões homoafetivas.

Há ainda aquelas situações em que o Debate Crítico Apreciativo é aberto à comunidade, em geral para que os tribunais possam ser mais bem esclarecidos da situação em análise, mediante a análise de argumentos, hipóteses e teorias. Também neles há profundo avanço no processo de objetivação, tal como ocorreu no julgamento pelo STF de demanda sobre a possibilidade de utilização de células tronco de embriões sobrantes em experiências científicas.

E mesmo no campo do direito probatório há situações de objetivação, como aquelas nas quais a utilização de determinadas espécies de prova deixam de ser aceitas ou tem seu valor probatório reduzido - são refutadas integral ou parcialmente - e outras passam a ser permitidas ou recebem maior valoração por possibilitarem maior verossimilhança, como é o caso dos exames de DNA em processos de investigação de paternidade. Essa objetivação no campo das provas é mais comum em demandas que requerem perícias técnicas.

Mas é necessário reconhecer que essa objetivação é imensamente maior em demandas repetitivas, como as que tratam de direitos individuais homogêneos, coletivos e difusos. Nos processos em que envolvem demandas individuais, não repetitivas, a presença da subjetividade é ainda muito forte.

Em todas essas situações o direito ao ser aplicado no mundo 1, mediado pela subjetividade do mundo 2 , não é mais a mera subjetividade desse mundo, mas a objetivação oriunda do embate das subjetividades, que retorna através de um ato de aplicação, ato esse que já estará limitado na sua subjetividade pelas possibilidades constituídas no mundo 3, o mundo objetivo.

Em última instância sabemos que será sempre necessário decidir entre diferentes possibilidades - decidir é inevitável. Mas devemos chegar a decisões através de argumentos racionais e não através de apelos emocionais, da retórica ou 
da força. São os argumentos racionais que podem ajudar-nos a chegar a uma decisão baseada na verossimilitude.

No campo do processo, como em todos os campos do direito, a Constituição nos oferece elementos para esse processo de objetivação. Os direitos fundamentais e os princípios constitucionais do processo são elementos fundamentais para a interpretação do direito como todo e, no que se refere ao nosso objeto, o direito processual. A interpretação do direito processual com base na idéia de acesso à justiça e do direito a aplicar com base nos direitos fundamentais permite a redução da subjetividade e o aumento da objetividade. A Constituição oferece os elementos necessários à objetivação da produção do conhecimento do direito, no processo e fora dele.

Não podemos justificar racionalmente uma hipótese (ou teoria), mas podemos justificar racionalmente uma preferência - é o que deve ocorrer no processo quando da fundamentação da decisão. Não há fontes autorizadas do conhecimento argumentos de autoridade não são argumentos válidos, quer seja com base em autores, quer seja com base de decisões de cortes superiores; os argumentos apresentados devem ser passíveis de análise crítica, racional.

Os pessimistas preferem realizar uma leitura totalmente subjetiva; dessa forma endossam visões relativistas, onde tudo, ou quase tudo, é possível. $E$ com isso muito pouco realizam de produtivo para os avanço das instituições jurídico-políticas e para o crescimento da objetividade e efetividade da prestação jurisdicional. É evidente que do Debate Crítico Apreciativo todas as visões devem participar; mas visões que negam os próprios resultados da crítica e se intitulam como as únicas visões críticas nada mais fazem do que, tentando monopolizar o discurso crítico, tornarem-se mais dogmáticas do que a visão dogmática que dizem combater.

A presença da subjetividade no ato de criação das teorias, no Debate Crítico Apreciativo e no ato de aplicação do direito é um fato. Não há como contestar. Mas disso não resulta que a aplicação do direito seja uma atividade puramente subjetiva. Recuperando Kelsen:

[...] na aplicação do Direito por um órgão jurídico, a interpretação cognoscitiva (obtida por uma operação de conhecimento) do Direito a aplicar combina-se com um ato de vontade em que o órgão aplicador do Direito efetua uma escolha entre as possibilidades reveladas através daquela mesma interpretação cognoscitiva. ${ }^{61}$

Nesse trecho da Teoria Pura do Direito, a primeira interpretação é a da Ciência do Direito - integrante do mundo 3 popperiano - e a segunda é a do aplicador - é o mundo 2 realizando a mediação entre o mundo 3 e o mundo 1 . O conhecimento produzido pela Ciência é conhecimento objetivo porque fruto da crítica intersubjetiva - mas não neutro, como quer Kelsen. O ato de aplicação é subjetivo, mas, como já dito anteriormente, não puramente subjetivo, porque sobre ele já atua o mundo 3, do conhecimento objetivo. ${ }^{62}$

O processo jurisdicional, por todos os fundamentos apresentados, é espaço de objetivação do direito - mesmo reconhecendo as limitações que lhe são inerentes. $O$ 
papel da Teoria do Processo, nesse contexto, é buscar através de um intenso Debate Crítico Apreciativo encontrar mecanismos mais efetivos para que essa objetivação se amplie.

\title{
HOW THE PROCESS AREA OF LAW OBJECTIFICATION HOW THE PROCESS OF SPACE LAW OF OBJECTIFICATION
}

\begin{abstract}
The object of this paper is to analyze the possibility of objectification law through the processes of legal interpretation and through the judicial process. The starting points are the positions that present subjectivity as central to the processes interpretation and application elements that are based on fundamentally axiological. In response to this reading is a reading built alternatively, based on the concept of world 3 proposed by Karl Popper in his work. In this theory, which composes the critical rationalism Popperian, the law must be located in the world 3, the objective world. They also worked on the concepts of approach of truth and falsifiability, based on the premise of eliminating the error. In this reading Debate Critical Appreciative is the central element of objectification law. It also presented the idea that the process is locus in the production and application of knowledge, and even acknowledged the subjectivity of the court act, you cannot deny that it also occurs objectification of Law.
\end{abstract}

Keywords: Application of Law. Approach of truth. Appreciative Critical Debate. Critical rationalism. Interpretation of Law. Karl Popper. Objectification of the Law. Objectivity. Process. Subjectivity. Truth. World 3.

\section{NOTAS}

Graduado em Direito pela FISC. Mestre e Doutor em Direito pela UFSC. Professor de Direito na UFSC - Graduação e Programa de Mestrado e Doutorado em Direito. E-mail: hwr1958@terra.com.br. Endereço: Universidade Federal de Santa Catarina, Centro de Ciências Jurídicas, Departamento de Direito - Campus Universitário, UFSC/CCJ - Sala 320 - Trindade, CEP 88040-400 - Florianópolis, SC - Brasil - Caixa Postal: 476.

1 Essa pureza kelseniana não se confunde com o processo de objetivação apresentado neste trabalho.

2 Cfe. KELSEN, Hans. Teoria pura do Direito. São Paulo: Martins Fontes, 2006.

3 Cfe. WARAT, Luis Alberto. Mitos e teorias na interpretação da lei. Porto Alegre: Síntese, 1979. e BRUM, Nilo Bairros de. Requisitos retóricos da sentença penal. São Paulo: Rev. Tribunais, 1980. WARAT, Luis Alberto. Mitos e teorias na interpretação da lei. Porto Alegre: Síntese, 1979.

5 Idem. Ibidem. p. 95.

Idem. Ibidem. p. 100.

7 WARAT, Luis Alberto. Introdução geral ao Direito I. Interpretação da lei: temas para uma reformulação. Porto Alegre: Fabris, 1994. p. 39.

10 Entende-se por linguagem natural aquela que é utilizada ordinariamente na comunicação comum e cujos signos possuem imprecisões significativas. Contrapõe-se ela às linguagens técnicas e unívocas, como a da matemática. 
11 WARAT. Mitos e teorias na interpretação da lei.

12 Cfe. KELSEN, Hans. Op. cit. p. 387-397.

13 Cfe. KELSEN, Hans. Op. cit. p. 396.

14 BRUM. Requisitos retóricos da sentença penal.

15 Em razão dos avanços na área da teoria do conhecimento sabe-se hoje que tanto em matéria de Direito como de provas, seja no cível ou no crime, só se pode chegar à aproximação da verdade e, em alguns casos, apenas à verdade formal, como nos casos de revelia.

O significante topos é o singular de topoi. Os topoi são diretrizes, lugares comuns revelados pela experiência e aptos a resolver questões vinculadas a círculos problemáticos concretos. Operam como fio condutor para toda a seqüência de argumentos que determinam o efeito de verossimilhança da conclusão. São elementos nos quais se buscam pontos de convergência e derivação para justificar um determinado ponto de vista. Operam, dessa forma, como ponto de referência de todos os argumentos e provas utilizados.

17 Ocorre, nessa situação, uma lacuna axiológica. Essa ocorre quando há uma norma legal aplicável a um caso concreto, mas a sua aplicação àquela situação específica leva a uma decisão injusta, que não está de acordo com os valores sociais hegemônicos.

18 Nilo Bairros de Brum (Op. cit.) utiliza o termo neutralidade para caracterizar este requisito, visto que em nível simbólico, o que se busca, segundo ele, é demonstrar a inexistência de escolhas axiológicas ou ideológicas na interpretação atribuída à lei. Entretanto, frente aos avanços ocorridos no campo da Epistemologia nos século XX entendemos não possuir sentido, nem no campo simbólico ou mesmo retórico, utilizar essa expressão frente à aceitação contemporânea, em todas as áreas, de que a neutralidade mesma inexiste.

19 As idéias de crítica intersubjetiva, verossimilitude, refutação e corroboração foram buscadas na obra de Karl Popper, como será demonstrado na seqüência deste capítulo. Entretanto a hipótese aqui apresentada não é uma posição presente na obra de Popper, mas uma leitura dos autores deste texto.

20 Como Popper não trabalhava com interpretações, mas sim com teoria e hipóteses científicas, é bem provável que não endossasse algumas das utilizações que fiz da sua teoria neste capítulo. Mas elas decorrem do Debate Crítico Apreciativo de sua própria teoria, realizado na busca de explicações para o que ocorre no mundo do Direito.

21 'No sentido lato 'Mundo 3' é o mundo dos produtos da mente humana; em sentido estrito é o mundo das teorias, incluindo as teorias falsas, e o mundo dos problemas científicos, incluindo questões relacionadas com a veracidade ou falsidade das várias teorias." (POPPER, Karl. A vida é aprendizagem. Epistemologia evolutiva e sociedade aberta. Lisboa: Edições 70, 2001. p. 43.). POPPER, Karl. Conhecimento objetivo. Belo Horizonte: Itatiaia; São Paulo: EDUSP; 1975. . O conhecimento e o problema corpo mente. Lisboa: Edições 70, 2002. Em busca de um mundo melhor. São Paulo: Martins Fontes, 2006. POPPER. O conhecimento e o problema corpo mente. p. 22, grifo do autor. Idem. Ibidem. Além dessas duas funções da linguagem, denominadas por Popper de funções superiores, ele indica, em seu obra $O$ conhecimento e o problema corpo mente duas funções inferiores, a expressiva e a comunicativa.

POPPER, Karl. O conhecimento e o problema corpo mente.

Idem. Ibidem.

Idem. Ibidem.

Idem. Ibidem. p. 46.

Idem. Ibidem.

Idem. Ibidem. p. 19. Grifos do autor.

POPPER. Em busca de um mundo melhor. p. 109.

POPPER, Karl. A lógica da pesquisa científica. São Paulo: Cultrix, 197-a. O conhecimento e o problema corpo mente. POPPER, Karl. Conhecimento objetivo. O conhecimento e o problema corpo mente. Em busca de um mundo melhor.

E é nesse sentido que essa expressão foi incorporado ao CPC de 1973 no dispositivo que trata da antecipação da tutela (art. 273).

POPPER, Karl. A vida é aprendizagem.

Idem. Ibidem. p. 36. Grifos do autor.

Idem. Ibidem. p. 39. Grifo do autor. 
39 "Obviamente que no sentido biológico e evolutivo em que falo do conhecimento, não só os animais e os homens têm expectativas e, portanto, conhecimento (inconsciente), mas também as plantas; e na realidade todos os organismos." (POPPER. A vida é aprendizagem. p. 88.). "[...] este esquema de como o novo conhecimento é adquirido se aplica desde a amiba a Einstein." (Idem. Ibidem. p. 24.).

40 Afirma Popper (Idem Ibidem.) que esse modelo pode ser entendido como o esquema geral da teoria da evolução de Darwin.

Entretanto, Popper ( $O$ conhecimento e problema corpo-mente) critica vários pontos da teoria de Darwin, propondo aperfeiçoamentos com base no seu esquema quadripartido..

41 POPPER, Karl. A vida é aprendizagem.

42 "Os cientistas, como todos os organismos, trabalham com o método da tentativa e erro. A tentativa é uma solução para um problema. Na evolução do reino animal ou vegetal o erro ou, para ser mais preciso, a correcção do erro, normalmente significa a erradicação do organismo; em ciência geralmente significa a erradicação da hipótese ou teoria." (Idem. Ibidem. p. 60).

Esse esquema pode ser encontrado no livro de Popper intitulado $O$ conhecimento e o problema corpo-mente (p. 23 e 25). Mas também é encontrado em várias outras de suas obras, inclusive com algumas variações nos símbolos utilizados.

44 EE, na obra de Popper, significa Experiência Empírica. Substituímos aqui esse significado clássico em sua obra, tendo em vista que no processo de tentativa e erro, na área do Direito, talvez não seja possível realizá-la sempre através de experiências empíricas, mesmo consideradas essas como o processo de observação. Talvez, porque há uma proposta de redefinição de como fazer Ciência do Direito adotando o modelo popperiano, que pode ser encontrada em: RODRIGUES, Horácio Wanderlei. A Ciência do Direito pensada a partir de Karl Popper. Intuitio , v.II, n 2, p.10-15, 2009. Disponível em: http://revistaseletronicas.pucrs.br/ojs/index.php/intuitio/article/view/5931.

45 "O esquema global indica que partimos de um problema, quer de natureza prática quer teórica; tentamos resolvê-lo elaborando uma teoria possível na qualidade de solução possível - é o nosso ensaio; em seguida, ensaiamos a teoria, procurando fazê-la abortar - é o método crítico de eliminação de erros; em resultado desse processo surge um novo problema, $\mathrm{P}_{2}$ (ou, quem sabe, vários novos problemas). [...]. Resumindo, o esquema diz-nos que o conhecimento parte de problemas e desemboca em problemas (até onde for possível ir)." (POPPER. O conhecimento e o problema corpo-mente. p. 23, grifo do autor).

46 POPPER, Karl. O mito do contexto. Em defesa da ciência e da racionalidade. Lisboa: Edições 70, 2009. P. 255.

47 A expressão método hipotético-dedutivo aparece na obra de Popper, na sua obra no livro $A$ miséria do historicismo (São Paulo: Cultrix, EDUSP; 1980. p. 102. Grifo nosso). "A isso tem-se dado o nome, por vezes, o nome de método hipotético-dedutivo ou , mas frequentemente, o nome de método da hipótese [...]."

48 Popper utilizou a expressão corroboração para descrever o grau de qualidade de uma hipótese submetida a testes. O que Popper ( $A$ lógica da pesquisa científica. p. 309.) denomina de "grau de corroboração de uma teoria é um relato sumário, em que se registra a forma pela qual a teoria resistiu aos testes a que foi submetida e a severidade dos testes." POPPER, Karl. A lógica da pesquisa científica.

Conhecimento objetivo.

50 Nessa situação o que ocorrerá, adotado o critério de demarcação proposto por Popper, é que esse conhecimento, mesmo decorrente de um processo de objetivação, não será considerado científico por não ser passível de teste empírico.

51 "A crítica, porém, só será frutífera se enunciarmos o problema tão precisamente quanto nos seja possível, colocando a solução por nós proposta em forma suficientemente definida - forma suscetível de ser criticamente examinada." (POPPER. A lógica da pesquisa científica. p. 536). POPPER, Karl. A miséria do historicismo.

53 POPPER. O conhecimento e o problema corpo-mente. p. 156. Grifos do autor.

54 Segundo Popper ( $A$ vida é aprendizagem), a discussão crítica é regida por idéias reguladoras, dentre as quais é necessário destacar: (a) a idéia de verdade; (b) a idéia de conteúdo lógico e empírico; e (c) a idéia de conteúdo de verdade de uma teoria e sua aproximação à verdade. POPPER, Karl. Conhecimento objetivo. O conhecimento e o problema corpo-mente.

56 POPPER, Karl. Conhecimento objetivo.

57 POPPER,Karl. Conjecturas e refutações. Brasília: UnB, 197-b. p. 343 
POPPER, Karl. A lógica das ciências sociais. Rio de Janeiro: Tempo Brasileiro; Brasília: UnB; 1978. p. 73-74.

59 Corroboração, não comprovação. Lembremo-nos que não temos como provar verdades, apenas como nos aproximar delas através de refutações pelo reconhecimento dos erros. Nesse sentido, todo conhecimento corroborado é provisório e pode ser superado.

60 Não se está aqui falando de conhecimento científico. A produção de conhecimento no processo é valorativa, escolha entre soluções possíveis; não é produção científica, embora na atividade jurisdicional processual se possa e deva utilizar dos conhecimentos produzidos pelas mais diversas ciências.

61 KELSEN. Op. cit. p. 394.

62 É preciso que se diga que em situações em que o Direito seja inadequadamente aplicado de forma consciente e deliberada, com o objetivo de obter vantagem ou de prejudicar a outrem, o problema não é de ausência de objetivação derivada da subjetividade do ato de aplicação. $O$ que há nessa situação é a prática de um crime. Também não há falha do processo de objetivação quando o aplicador é induzido em erro pela partes, como ocorre em situações de falsificação de provas. Fraudes e má-fé não estão restritas às áreas do Direito e da política. Elas ocorrem em todas as áreas e atividades, em menor ou maior grau. São inclusive públicas e conhecidas mesmo em áreas tradicionais como a Física, a Biologia e a Arqueologia, dentre outras.

\section{REFERÊNCIAS}

BRUM, Nilo Bairros de. Requisitos retóricos da sentença penal. São Paulo: Rev. Tribunais, 1980.

KELSEN, Hans. Teoria pura do Direito. São Paulo: Martins Fontes, 2006.

POPPER, Karl. A lógica da pesquisa científica. São Paulo: Cultrix, 197-a. . Conjecturas e refutações. Brasília: UnB, 197-b.

. Conhecimento objetivo. Belo Horizonte: Itatiaia; São Paulo: EDUSP; 1975. . A lógica das ciências sociais. Rio de Janeiro: Tempo Brasileiro; Brasília:

UnB; 1978.

. A ciência normal e seus perigos. In: LAKATOS, Imre; MUSGRAVE, Alan

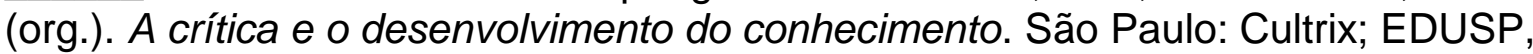
1979. p. 63-71.

. A miséria do historicismo. São Paulo: Cultrix; EDUSP, 1980.

O racionalismo crítico na política. Brasília: UnB, 1981.

O realismo e o objectivo da ciência. Lisboa: Dom Quixote, 1987. (Pós-

escrito a lógica da descoberta cientifica - v. I).

. Sociedade aberta, universo aberto. Lisboa: Dom Quixote, 1995.

. A sociedade aberta e seus inimigos. Belo Horizonte: Itatiaia; São Paulo:

EDUSP; 1998. 2 v.

. A vida é aprendizagem. Epistemologia evolutiva e sociedade aberta. Lisboa:

Edições 70, 2001.

O conhecimento e o problema corpo-mente. Lisboa: Edições 70, 2002.

Em busca de um mundo melhor. São Paulo: Martins Fontes, 2006.

Los dos problemas fundamentales de La Epistemologia. Basado em

manuscritos de los años 1930-1933. 2. ed. Madrid: Tecnos, 2007.

O mito do contexto. Em defesa da ciência e da racionalidade. Lisboa:

Edições 70, 2009.

WARAT, Luis Alberto. Mitos e teorias na interpretação da lei. Porto Alegre: Síntese, 1979.

O Direito e sua linguagem. $2^{\mathrm{a}}$ versão. Porto Alegre: S. Fabris, 1984.

Introdução geral ao Direito I. Interpretação da lei: temas para uma

reformulação. Porto Alegre: Fabris, 2004. 
Recebido para publicação: 10/10/2010

Aceito para publicação: 20/12/2010 